\title{
Story Behind the Beautify Smile: A Case Report
}

\author{
Preeti Mishra', Shalya Raj2, Rohit Ravinder ${ }^{3}$, Akanksha Jain 4 \\ ${ }^{1}$ Lecturer, Department of Conservative and Endodontics, Subharti Dental College, Meerut (U.P.), India. \\ ${ }^{2}$ Reader, Department of Conservative and Endodontics, Subharti Dental College, Meerut, (U.P.), India. \\ ${ }^{3}$ Reader, Department of Conservative and Endodontics, Subharti Dental College, Meerut (U.P.), India. \\ ${ }^{4}$ Private Practitioner, Jaipur, India.
}

Case Report

Address for Correspondence Author

Dr. Preeti Mishra; Department of Conservative and Endodontics, Subharti Dental College, Meerut (U.P.), India.

E-mail: preeti.prajesh@gmail.com

Crossref doi: https://doi.org/10.36437/ijdrd.2020.2.3.B

\begin{abstract}
Solving esthetic problems in the anterior teeth is a challenge for the restorative dentist. For many years, full coverage restorations were the most highly preferred treatment for esthetic defects. However, such restorations are invasive and cause great loss of tooth structure. Enhancing and maintaining the life-like quality of the tooth is the story behind the beautiful smile. This article addresses the successful management of esthetic rehabilitation of anterior dentition using an all-ceramic crown and veneer.
\end{abstract}

Keywords: All-Ceramic, Esthetic, Maxillary incisor, Veneer.

\section{Introduction}

Smile is one of the most important facial expressions and is essential in expressing emotions. An attractive or pleasing smile enhances the acceptance of an individual in society by improving interpersonal relationships. Webster defines the smile as "a change of facial expression involving a brightening of the eyes, an upward curving of the corners of the mouth with no sound and less muscular distortion of the features than in laugh". For seeking attractiveness on face "a beautiful/pleasing smile" is required. Hence, Patients seek dental treatment for esthetics. The goal of anesthetic treatment is to enhance the beauty, pleasing impulse but with natural appearance keeping in mind the functional and biological requirements of the patient. So a big confusion arises that when a patient is a public figure than how to provide immediate psychological relief. Can we as an Endodontist help out this type of patient when the structural malpositioning is affecting the esthetics? This paper present the case report of successful management of esthetic rehabilitation of malpositioning anterior teeth with all-ceramic crown and veneer.

\section{Case report}

A 22 years old female patient reported to the Department of Conservative Dentistry and Endodontics, Subharti Dental College and Hospital, Meerut with the chief complaint of a fractured segment and irregularly placed teeth in upper front tooth region of the jaw and wanted esthetic rehabilitation for the same. The patient does not want to undergo orthodontic treatment. Medical history was found to be non-contributory. Past dental 
history revealed that the patient had undergone root canal treatment irt 11 three months ago. Clinical examination revealed Ellis class 3 fracture in proclined right maxillary central incisor while left maxillary central incisor was retroclined (Figure a,b). Pulp vitality testing demonstrated no response in 11 whereas 21 demonstrated positive response. The diagnostic IOPA radiograph of 11,21 suggested root canal treatment in 11 with no sign of apical periodontitis. Occlusal examination revealed normal Class I occlusion with functional canine and incisal guidance. No signs of parafunction habits were observed. Based on the above clinical and radiographic findings, a diagnosis of RCT treated 11 with ELLIS class III fracture and retroclined vital 21 was made. Hence, a treatment plan of the full-coverage ceramic crown in 11 and ceramic veneer in 21 was decided.

The shade selection was shared with the ceramist, using photographs and spectrometer (VITA Easyshade). The tooth was prepared for all-ceramic crown and veneer and impression with polyvinyl siloxane impression material (Coltene Whaledent, Altstatten, Switzerland) was taken (Figure c). Leucite glass-ceramic crown and veneer (IPS Empress, Ivoclar Vivadent, USA) was processed in the laboratory (Figure d). Preparation of the crown and veneer were performed with 5\% Hydrofluoric acid (ceramics etch, VITA, Zahnfabrik, Bad Sackingen, Germany) for 60 seconds, rinsed and air-dried then a silane agent (Monobond S, Ivoclar Vivadent, Schaan, Liechtenstein) was applied, left undisturbed for $60 \mathrm{sec}$ and then air dired. After that crown and veneer were cemented with a self-adhesive cement (RelyX Unicem, 3M ESPE, Seefeld, Germany). The crown was seated applying slight pressure and cement was allowed to self-cured for 3 minutes and then the excess was removed with the help of sickle scaler. Photopolymerization was performed with a light-curing device(Demetron Demi LED, Kerr Corporation, CA, USA) for 60 secs from occlusal, lingual, buccal, mesial, and distal surfaces. After polymerization, the margins were polished using flexible aluminium oxide discs of different grain sizes (Sof-Lex, 3M ESPE). (Figure e,f)

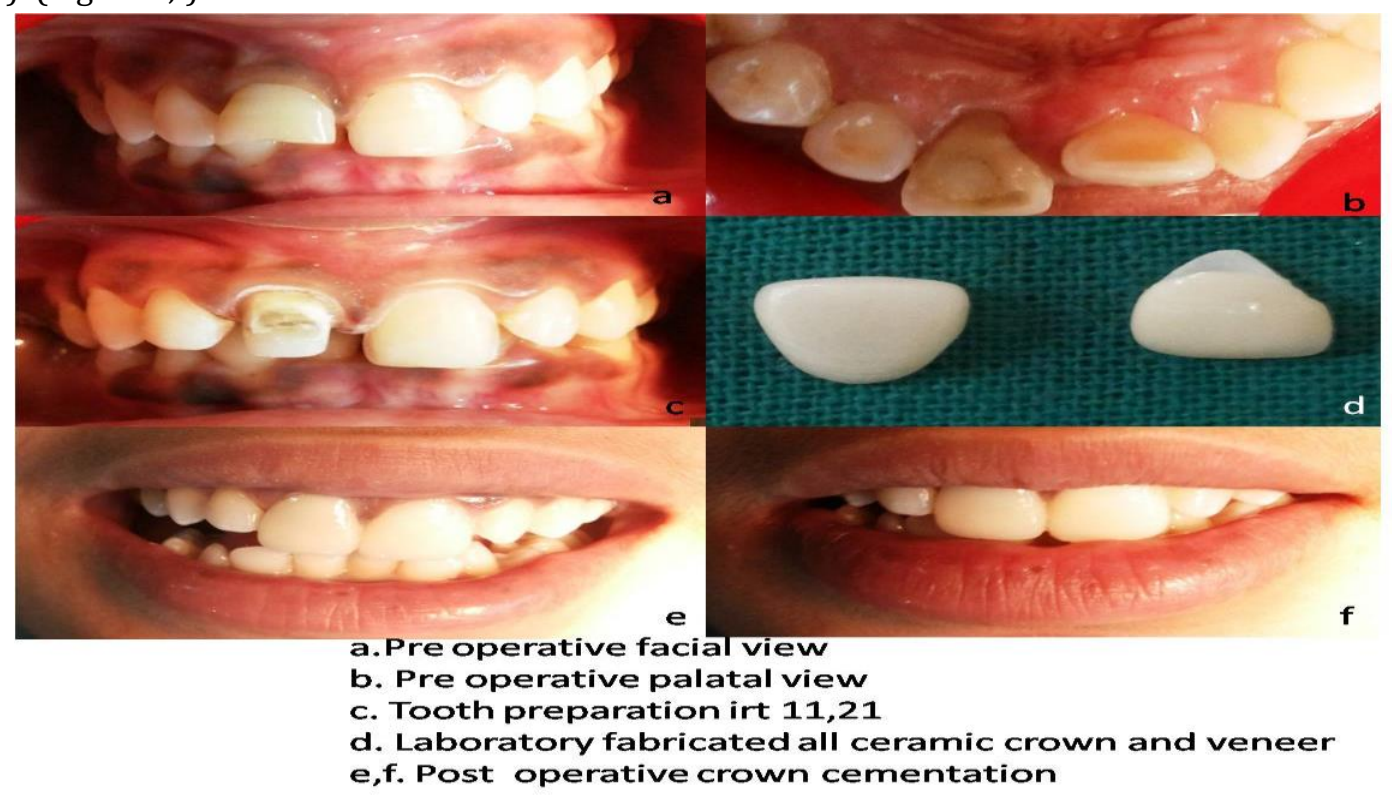

\section{Discussion}

As people retain their teeth for much longer than in the past, the need for aesthetically acceptable restorations is continuing to increase. ${ }^{1}$ Dentists have searched for the ideal restorative material for many years.

Ceramic materials now have a firmly established role in many aspects of clinical dentistry. Dental ceramics are known for their natural appearance and their durable chemical and optical properties. However, dentists have remained suspicious of the structural longevity, potential abrasivity, and fit of ceramic restorations. Recent 
dental research in ceramics has addressed issues of clinical survival, response during wear, and fit. These concerns have directly influenced the development of recently introduced ceramic materials and laboratory processing systems. ${ }^{2}$

Dentists and their laboratory technicians must understand the benefits and limitations of the properties of dental ceramics and their design requirements to minimize the risk for catastrophic fractures that require costly repairs or replacement and which cause patients to make potentially unnecessary return visits to the dental office. Hence, an understanding of properties, processing, and design factors play a major role in ensuring the long-term clinical success of ceramic-based prostheses. ${ }^{3}$

Ceramic restorations are indicated where aesthetics is needed and when the size of the preparation exceeds the limit for the use of direct composite resins.

Leucite glass-ceramic was the material of choice because it allows for adhesive cementation. In veneer tooth, preparation tooth preparation is within the enamel and even tooth preparation for crown also has margins located on enamel. The patient did not present any parafunctional habits that are why this material was a feasible choice. Further, the longevity of IPS Empress system for both crown and veneer has been well established. $4,5,6,7$

\section{Conclusion}

A restoration can last for a lifetime if its structure is fabricated and maintained efficiently following all the principles. The cumulative visual impact of a smile cannot be associated exclusively with the beauty of individual teeth. Smile design is a relatively multidisciplinary approach. Therefore, the achieved smile is not an ideal smile rather it is a balanced smile, which can be described as an adequate positioning of teeth within themselves, and with the gingiva and soft tissues, to have perfect harmony in these components to achieve a pleasing look of the patient with fulfilling their biological as well as functional need.

\section{References}

1. Introduction to Dental Materials: Richard Van Noort: $2^{\text {nd }}$ Edition.

2. J. Robert Kelly, Ichiro Nishimura, Stephen D. Campbell. Ceramics in dentistry: Historical roots and current perspectives. J Prosthet Dent 1996; 75:18-32.

3. Phillips Science of Dental Materials: $11^{\text {th }}$ Edition 2003.

4. Conrad HJ, Seong WJ, Pesun IJ. Current ceramic materials and systems with clinical recommendations: A systematic review. J Prosthet Dent 2007; 98:389-404.

5. Della BA, Kelly JR. The clinical success of all ceramic restoration. J Am Dent Assoc 2008; 139:8-13.

6. Guess PC, Stappert CFJ. Midterm results of a 5 year prospective clinical investigation of extended ceramic veneers. Dent Mater 2008; 24:804-13.

7. Fradeani M, Redemagni M. An 11 year clinical evaluation of leucite-reinforced glass ceramic crown: A retrospective study. Quintessence Int 2002; 33:503-10.

How to cite this Article: Preeti Mishra' ${ }^{1}$, Shalya Raj², Rohit Ravinder ${ }^{3}$, Akanksha Jain ${ }^{4}$ : Story

Behind the Beautify Smile: A Case Report

Int. J. Drug Res. Dental Sci., 2020; 2(3):6-8.

Crossref doi: https://doi.org/10.36437/ijdrd.2020.2.3.B

Source of Support: Nil, Conflict of Interest: Nil.

Received: 20-6-2020 Revised: 22-7-2020 Accepted: 28-7-2020 